\title{
Pembangunan Jiwa Pendidik dalam Kalangan Bakal Pendidik
}

\author{
Rohana Hamzah ${ }^{a^{*}}$, Tengku Norzaini Tengku Ibrahim ${ }^{a}$, Sarimah Ismail ${ }^{\mathrm{a}}$, Ros Eliana Ahmad Zuki \\ a Jabatan Pendidikan Teknikal dan Kejuruteraan, Fakulti Pendidikan, Universiti Teknologi Malaysia 81310 UTM Johor Bahru, Johor \\ *Corresponding author: anahaiqal@yahoo.com
}

\section{Article history}

Received :23 September 2012

Received in revised form : 10

February 2013

Accepted : 20 February 2013

\begin{abstract}
Producing high quality human capital is the main agenda in our education system. Therefore, the intent should be transformed with full commitment, compassionate and dedicated by every educator. However, lack awareness of the real meaning and aim of education among trainee educator will reduce our possibility to achieve the agenda. Therefore, the purpose of this study is to determine strength of educator's soul development among final year students (trainee educator) from Faculty of Education UTM. Quantitative research design has been used to collect data from 89 respondents which is the whole population of study. The reliability value 0.93 has been obtained using Cronbach Alpha and the value shows that the research instrument is reliable to fulfill the purpose of this study. The finding shows that, the strength of educator's soul development among final year students is moderately high with mean value at 3.86. The finding also shows that trainee educator's level of attentiveness toward education aim which is to develop human potential based on universal value belief and devotion to God obtain the lowest mean 3.62 which is at the moderate level. Therefore, there is essential to put more effort to strengthen trainee educators' attentiveness towards the real aim of education.
\end{abstract}

Keywords: Human capital; educator soul; education aim

\begin{abstract}
Abstrak
Mendidik dan melahirkan modal insan berkualiti merupakan hasrat dan agenda utama sistem pendidikan Negara. Oleh itu, hasrat ini merupakan amanah besar yang perlu dijelmakan oleh setiap warga pendidik dengan penuh komitment, prihatin dan dedikasi. Kurangnya penghayatan terhadap makna dan matlamat pendidikan dalam kalangan bakal pendidik akan menjejaskan hasrat murni tersebut. Oleh itu kajian ini bertujuan untuk mengenal pasti tahap pembangunan jiwa pendidik dalam kalangan bakal guru di UTM. Reka bentuk kajian ini ialah kuantitatif dan melibatkan keseluruhan populasi kajian. Seramai lapan puluh sembilan pelajar telah terlibat sebagai responden. Nilai kebolehpercayaan instrumen yang telah dibina ialah 0.93. Dapatan kajian menunjukkan bahawa tahap penghayatan jiwa pendidik memperolehi min sebanyak 3.86 iaitu tahap sederhana tinggi. Dapatan juga menunjukkan penghayatan bakal pendidik terhadap matlamat pendidikan untuk membangunkan potensi manusia berteraskan visi nilai universal kepercayaan dan kepatuhan kepada Tuhan mendapat min yang terendah pada tahap sederhana iaitu 3.62. Oleh itu terdapat keperluan untuk memantapkan penghayatan jiwa pendidikan dalam kalangan bakal guru terutamanya tentang matlamat pendidikan.
\end{abstract}

Kata kunci: Modal insan; jiwa pendidik; matlamat pendidikan

(C) 2013 Penerbit UTM Press. All rights reserved.

\subsection{PENGENALAN}

Pembangunan modal insan yang berkualiti adalah teras kepada kejayaan bangsa dan negara. Ia merangkumi satu proses yang lengkap dalam membentuk manusia berilmu, berakhlak mulia, berkemahiran dan berdaya tahan. Forget (1997), dalam artikelnya yang bertajuk "Investing in Human Capital" telah mengulas mengenai betapa pentingnya menjana modal insan sebagai elemen teras dalam agenda pembangunan negara. Kegagalan membangunkan modal insan berkualiti boleh merencat banyak lagi potensi pertumbuhan yang mampu di capai oleh sesebuah negara. Dengan perkataan lain, jatuh dan bangun sesebuah negara sememangnya bergantung kepada modal insannya. Tanpa modal insan yang mantap lagi padu, bukan saja bangsa menjadi mundur, malah sesebuah tamadun mungkin mengalami kemerosotannya.Oleh itu sejauh mana kejayaan guru dalam membina generasi yang berminda kritis, mampu meneroka dan menyebarkan ilmu pengetahuan, berani mencuba sesuatu yang baru, kreatif dan inovatif serta memiliki kualiti peribadi yang unggul menjadi faktor utama dalam penentuan sama ada negara mampu bersaing dan mencorak masa hadapan yang gemilang atau tidak.

Guru harus berkemampuan untuk membentuk pelajar agar memiliki keperibadian dan berakhlak mulia. Oleh itu, kerjaya seorang guru memerlukan komitmen yang tinggi dan disertai dengan niat yang ikhlas dalam mendidik pelajar. Menurut 
Jahangir Mahmud (2010), guru perlu berperanan sebagai pengurus, fasilitator, ahli psikologi, pakar rujuk, inovator, penilai, agen perubahan dan pemimpin. Dalam kepelbagaian peranan seorang guru, guru seharusnya memiliki sifat dan kualiti yang baik dari segi peribadi, professional dan sosial. Maka, guru yang menghayati tugasnya sebagai pendidik atau guru berjiwa pendidik seharusnya memiliki kualiti peribadi dan sosial yang baik agar dapat menjalankan tugas sebagai pendidik dengan lebih sempurna.

Dengan perkataan lain, kunci kepada usaha untuk melahirkan insan berkualiti bergantung kepada kualiti insan guru itu sendiri. Guru yang berjiwa pendidik pasti mampu membimbing pelajarnya untuk memiliki nilai keinsanan dengan kualiti peribadi dan jalinan sosial yang baik. Menurut Rashidy Jamil al-Rashid (2011), bagi meningkatkan kualiti peribadi seorang pendidik, pendidik seharusnya membersihkan jiwanya terlebih dahulu sebelum membimbing manusia. Para pendidik juga perlu jelas tentang ke arah manakah pelajarnya perlu dibimbing. Oleh itu matlamat atau tujuan pendidikan perlu jelas di kalangan para pendidik sebelum mereka boleh membimbing pelajar ke jalan yang lurus dan seterusnya mampu membezakan di antara kebenaran dan kepalsuan (Wan Mohd. Noor, 2005). Menerusi pembersihan jiwa juga, maka lahirlah akhlak-akhlak Islam yang menjadi penyuluh kepada jiwa pelajar yang berada di bawah didikan seorang pendidik. Kepincangan akhlak bagi seorang murabbi (pendidik) sudah pasti membawa kepada runtuhnya keberkatan ilmu dan tarbiyah yang disampaikan ke dalam jiwa masyarakat.

Sehubung dengan itu, terdapat satu keperluan yang signifikan untuk mengkaji kualiti jiwa pendidik bakal guru sebelum mereka melangkah ke alam kerjaya sebagai seorang pendidik.

\subsection{GURU BERJIWA PENDIDIK PERLU MENGHAYATI MAKNA DAN TUJUAN PENDIDIKAN}

Seorang guru berjiwa pendidik seharusnya memiliki kefahaman yang mantap terhadap tujuan atau matlamat pendidikan itu sendiri. Pada asasnya tujuan pendidikan ialah untuk perubahan sikap dan tingkah laku manusia (Yahya Jusoh dan Azhar Muhammad, 2007). Namun proses perubahan sikap memerlukan ilmu yang bermakna, ilmu yang diyakini kebenarannya oleh pelajar sehingga akhirnya mampu menyentuh hati dan akal fikirannya dan seterusnya mengubah cara hidup atau jalan kehidupannya (Syed Abul A'la Al-Maududi, 1987).

Oleh itu pendidikan bukan sekadar bermaksud proses memasukkan ilmu atau memindahkah ilmu ke minda manusia malah ia merupakan satu proses membimbing makna apa yang dipelajari dengan lebih mendalam. Oleh itu pendidikan bertujuan mendidik manusia agar mampu memahami makna di sebalik apa yang dipelajari dan seterusnya mampu memperkembangkan potensi dirinya sendiri, menerokai dan menyintai kebenaran serta mampu berfikir dan bertindak secara adil dan bijaksana (Syed Naquib al-Attas, 2001).

Persoalannya apa yang dikatakan sebagai makna yang mendalam dalam proses pendidikan? Menurut Hasan Langgulung (2003) dan Rohana (2009a), proses pendidikan seharusnya membawa manusia menyedari, kesaksian akan bukti dan tandatanda kewujudan Tuhan sebagai pemilik kuasa tertinggi (infinitif) melalui proses pembelajaran dan penerokaan ilmu pengetahuan intelektual (Hasan Langgulung, 2003; Rohana, 2009a). Proses pemerhatian dan pembelajaran ilmu intelektual membawa pelajar mengerti tentang rahsia disebalik kewujudan alam fizikal. Dalam erti kata lain guru sebagai pendidik perlu membimbing potensi intelektual pelajar untuk membangunkan potensi spiritual yang merupakan asas kepada pembangunan jati diri pelajar (Rohana, 2010).

Proses pendidikan juga dikenali sebagai proses transformasi potensi-potensi manusia dengan matlamat atau tujuan mengenali hakikat diri iaitu menjawab dua persoalan penting tentang siapa diri saya dan apa tujuan hidup saya (Ahmad Sabri, 2003). Dua persoalan penting ini akan membawa manusia menghayati konsep kebebasan diri berdasarkan prinsip kebenaran universal iaitu bertuhankan dan memperhambakan diri hanya kepada Tuhan yang menciptanya dan sekalian alam seperti mana dijelaskan di dalam ayat di bawah:

Allah membuat perumpamaan iaitu seorang hamba yang dimiliki oleh beberpa tuan yang sering dalam perselisihan dan seorang hamba yang dimiliki sepenuhnya oleh seorang tuan sahaja. Adakah kedua-dua hamba ini sama keadaanya?

(Surah Az-Zumar, ayat 29)

Persoalan pertama bertujuan untuk membangunkan jati diri manusia untuk menghayati erti kebebasan diri berdasarkan kepada prinsip kebenaran yang kekal abadi iaitu keyakinan dan kepercayaan kepada Tuhan. Pergantungan manusia kepada kuasa infinitif ini yang Maha Melihat apa yang nyata dan tersembunyi di lubuk hati manusia akan mampu membangkitkan jati diri dan kawalan dalaman individu. Kawalan dalaman yang teguh akan melahirkan ketenangan dan seterusnya membangkitkan akhlak terpuji seorang insan. Oleh itu pendidikan bukan sekadar tentang latihan kemahiran atau pemikiran tetapi turut mencakupi pembangunan jati diri pelajar (Wan Mohd. Nor, 2005). Inilah matlatmat tertinggi yang perlu dihayati oleh seorang guru berjiwa pendidik.

Ilmu tanpa amal ibarat pohon yang rimbun tanpa buah. Ia tidak mampu memberi kesan kepada diri seseorang apatah lagi persekitaran kehidupannya. Oleh itu persoalan kedua pula iaitu berkenaan dengan "apakah tujuan hidup saya" bertujuan membimbing manusia tentang tanggungjawab sosialnya sebagai seorang khalifah atau pemimpin perubahan untuk mengerjakan kebaikan atau amal soleh (Rohana, 2010).

Sekiranya kita perhatikan, semua yang ada disekeliling kita sedang mengalami perubahan ataupun lebih dikenali sebagai evolusi. Namun perubahan ini memerlukan pimpinan agar ia berlaku atau dilakukan berdasarkan perintah Pencipta. Oleh itu Allah (S.W.T.) telah melantik manusia sebagai khalifah atau pemimpin perubahan di muka bumi ini. Maka tujuan manusia diciptakan untuk memainkan peranan sosial sebagai khalifah perlu di didik melalui proses pendidikan agar perubahan yang dilakukan tidak menyebabkan kemusnahan atau kezaliman baik kepada dirinya sendiri, orang lain dan makhluk lain di alam ini. Nilai kesedaran tujuan kehidupan sebagai khalifah akan memimpin akhlak manusia di dalam melakukan perubahan yang bermula daripada proses memimpin perubahan diri, keluarga, masyarakat, negara dan dunia dalam menjelmakan keimanan dan mematuhi perintah Pencipta.

Para pendidik perlu sedar bahawa setiap pelajar perlu dididik untuk berpegang kepada prinsip kebebasan universal dan mereka perlu berperanan sebagai pemimpin yang bertanggungjawab kepada proses perubahan diri, jalinan sosial dengan orang lain dan persekitaran kehidupannya dengan adil. Walau bagaimanapun, matlamat sosial tanggungjawab sebagai khalifah atau pemimpin perubahan ini tidak akan dapat dididik dengan sempurna selagi pelajar tidak dapat menyakini dan menghayati matlamat hidup yang pertama iaitu kepercayaan, keyakinan dan kehambaan hanya kepada Pencipta sekalian alam. Dua matlamat penting pendidikan inilah yang telah terhakis di dalam sistem pendidikan sekular atau sistem pendidikan yang diasaskan oleh penjajah (Sidek, 2011). 
Secara ringkasnya, proses pendidikan berdasarkan dua persolan diatas boleh digambarkan seperti di dalam rajah berikut:

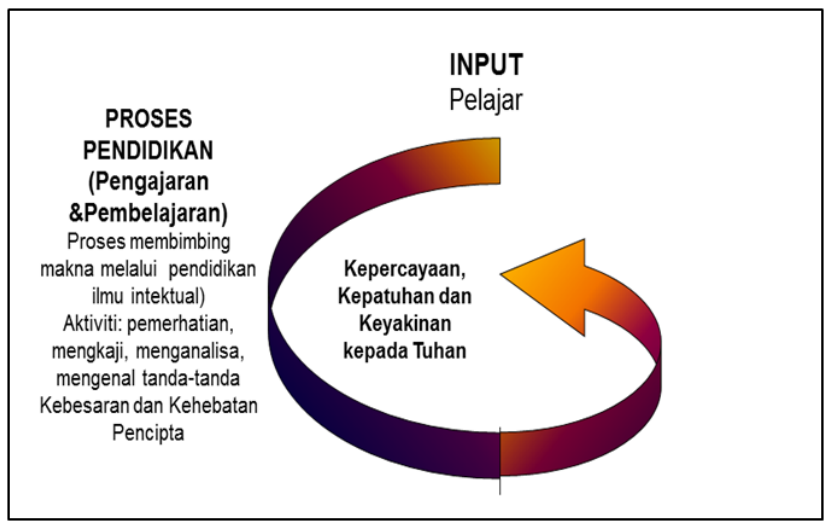

Rajah 1 Proses bimbingan makna ilmu intelektual melalui aktiviti P\&P oleh guru berjiwa pendidik

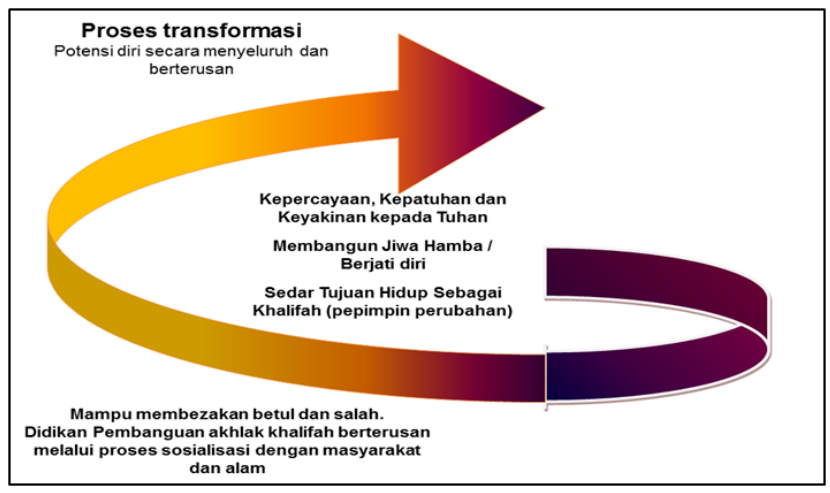

Rajah 2 Proses Bimbingan pembangunan akhlak khalifah berterusan melalui aktiviti P\&P oleh guru berjiwa pendidik

Sekiranya dianalisis kembali Falsafah Pendidikan Negara (FPN), dengan jelas dinyatakan proses pembangunan potensi manusia secara menyeluruh perlulah disandarkan kepada prinsip kepercayaan dan keyakinan manusia kepada Tuhan. Oleh itu pembangunan asas kepercayaan dan keyakinan kepada Tuhan perlu dijadikan visi utama proses pendidikan yang perlu dihayati oleh guru berjiwa pendidik dan ia menjadi prasyarat untuk melahirkan insan berakhlak mulia. Ghazali (1986) menyatakan ramai ilmuan Islam bersependapat bahawa pengajaran yang mengaitkan antara mesej ilmu wahyu dengan ilmu dari kecerdasan akal dapat membentuk manusia yang lebih baik, cekal, bijaksana dan rapat dengan Penciptanya iaitu Allah S.W.T.

Malangnya proses pengajaran dan pembelajaran pada masa kini lebih dipengaruhi oleh pendekatan sekular dan teori-teori pendidikan barat seperti teori tingkah laku, kognitif dan humanism yang pada dasarnya dikembangkan berdasarkan pemikiran yang melihat perkembangan potensi manusia dari segi jamani, rohani, emosi dan intelektual secara terpisah-pisah. Proses pengasingan antara perkembangan ilmu intelek dengan nilai tertinggi iaitu kepercayaan dan keyakinan kepada kewujudan Pencipta inilah yang dikenali sebagai sekularisasi (Ghazali, 1986).

Pemisahan ilmu inilah kejayaan fahaman sekular yang didokongi oleh masyarakat barat atau masyarakat berpendidikan barat sehingga menyebabkan pemikiran masyarakat Malaysia terjajah dan lebih suka menjadi pengikut dari penjadi pengasas atau pemimpin. Untuk melepaskan diri dan anak bangsa dari kongkongan ini, menjadi tugas pendidik untuk menyepadukan kembali perkembangan ilmu intelektual dengan ilmu wahyu(Rohana, 2009b). Kepentingan penggabungan kembali kedua ilmu ini juga disedari oleh pengkaji barat. Love dan Talbot (1999), menyatakan bidang kerohanian dan pembangunan spiritual amat jarang diperkatakan di dalam pengajian tinggi mahupun dalam penulisan kajian pelajar. Kepentingan pembangunan spiritual dapat dilihat dari Misi Nasional, Pelan Induk Pembangunan Pendidikan dan misi Universiti Teknologi Malaysia yang mengimpikan warganegara yang seimbang antara fizikal dan rohani. Namun begitu, sekiranya bidang pendidikan gagal untuk membuat penyatuan perkembangan ilmu intelektual dengan pembangunan spiritual, ia mungkin menyumbang kepada halangan terhadap pengukuhan kepercayaan terhadap agama, ketidakupayaan untuk berfikir secara kritikal, tidak sensitif dengan isu yang berkaitan dengan nilai dan etika dan tidak mahu bertanya (Love dan Talbot, 1999).

\section{Q3.0 PERBEZAAN DIANTARA GURU BERJIWA PENDIDIK DAN PENGAJAR}

Guru berperanan sebagai murabbi (pendidik), tidak sekadar mualim (pengajar). Hal ini kerana peranan mualim berfokuskan pengajaran manakala murabbi berfokus pendidikan. Mualim ialah individu yang berperanan menyampaikan ilmu yang berbentuk agama (fardu ain) ataupun akademik (fardu kifayah). Matlamat utama pengajar adalah agar ilmu yang diberikan itu dapat difahami dan diaplikasikan semula semasa peperiksaan (Muhammad Jihad, 2008: 21).

Menurut Muhammad Jihad (2008: 21-22), murabbi berperanan mendidik jiwa muridnya supaya jiwa muridnya terkesan oleh ilmu yang diberikan. Ilmu itu kemudiannya dihayati, diyakini dan kemudiannya diamalkan dalam kehidupan. Tegasnya, tugas murabbi lebih tinggi daripada mualim kerana memerlukan sesuatu ilmu bukan sahaja difahami, tetapi dihayati sekali gus membentuk keperibadian, sikap dan tabiat pelajarnya. Jika tugas mualim banyak berlegar pada akal, maka tugas murabbi pula adalah di dalam hati pelajarnya.

Sekali lagi dua definasi ini menunjukkan seorang guru berjiwa pendidik memiliki kemampuan untuk mendidik hati pelajar dengan memberi makna yang lebih mendalam terhadap ilmu intelektual (ilmu daripada hasil pemerhatian) yang dipelajari. Sentuhan akal dan hati ini akan menghidupkan emosi yang lebih stabil dan positif dan seterusnya membentuk akhlak yang baik. Maka, seorang pendidik yang berjaya ialah seorang pendidik yang mampu melahirkan pelajar berakhlak dan bertanggungjawab seperti yang dinyatakan di dalam sebuat hadis dari Ibnu 'Amru r.a. yang meriwayatkan sabda Rasullulah s.a.w:

\section{"Sebaik-baik manusia itu ialah mereka yang paling baik akhlaknya."}

(Abdul Ghani, 2002: 408)

\subsection{PERNYATAAN MASALAH}

Guru bukanlah sebagai robot ataupun alat untuk menyampaikan ilmu sahaja. Mereka perlu memainkan peranan yang lebih meluas lagi (Pusat Perkembangan Kurikulum, 1988). Antaranya untuk menanam nilai-nilai murni melalui keilmuan dan pendidikan bagi menghidupkan potensi-potensi dalaman dan luaran dalam diri murid supaya dapat berkembang dan berfungsi dengan sebaikbaiknya sebagaimana yang diperintahkan oleh Allah S.W.T.

Namun, kebelakangan ini isu tentang kualiti para pendidik sering dipersoalkan di mana, pendidik itu sendiri tidak memiliki 
sifat dan sikap seorang pendidik yang sepatutnya perlu ada dalam melahirkan guru yang komited dengan kerja sebagai pendidik. Menurut Mok Soon Sang (2003), di antara sifat yang perlu ada di dalam diri seorang pendidik adalah baik hati, jenaka, sabar, bertanggungjawab, yakin dan kepimpinan. Sifat-sifat tersebut dapat melahirkan seorang pendidik yamg memiliki ciri-ciri kejujuran, berpandangan jauh, berinspirasi, ketrampilan, adil, menyokong, berfikiran terbuka, bijak, berterus terang, boleh diharapkan dan bekerjasama (Kouzes dan Posner, 1993). Justeru itu, pendidik yang berkesan tidak semata-mata menitikberatkan aspek pencapaian akademik dan peperiksaan awam semata-mata tetapi bertekad untuk menyampaikan input-input bagi melahirkan pelajar sekolah yang menyeluruh (holistik) seperti mana yang terkandung di dalam Falsafah Pendidikan Kebangsaan.

Oleh itu kajian ini bertujuan untuk melihat tahap kemantapan pembangunan jiwa pendidik yang diukur berdasarkan pengetahuan bakal pendidik tentang tujuan proses pendidikan.

\subsection{REKA BENTUK KAJIAN}

Reka bentuk kajian ini ialah kajian tinjauan kuantitatif yang menggunakan soal selidik sebagai instrumen kajian. Instrumen kajian ini telah dibina berdasarkan objektif kajian dan mendapat kesahan daripada dua orang pensyarah dari Jabatan Pendidikan Teknikal dan Kejuruteraan, Fakulti Pendidikan, UTM Skudai. Ujian kebolehpercayaan pula telah dijalankan dengan melibatkan 17 orang responden Sarjana Muda Sains serta Pendidikan (Kimia) secara rawak mudah kerana mereka di dapati mempunyai ciri-ciri yang sama dengan populasi kajian. Nilai Alpha-Cronbach adalah 0.927. Kajian ini telah melibatkan keseluruhan populasi kajian iaitu seramai 89 orang pelajar tahun akhir dari Kursus SPE, SPJ, dan SPH, Fakulti Pendidikan UTM.

\subsection{DAPATAN KAJIAN}

Berikut adalah dapatan kajian bagi item-item yang telah dibina untuk mengukur tahap pengetahuan bakal pendidik terhadap tujuan proses pendidikan.

Jadual 1 Tahap pengetahuan bakal pendidik tentang tujuan proses pendidikan

\begin{tabular}{|lll|}
\hline Item (Tujuan pendidikan; Keyakinan dan kepercayan kepada Pencipta) & Min & Tahap \\
\hline $\begin{array}{l}\text { Sebagai pendidik, saya perlu menyuburkan sikap kepercayaan } \\
\text { kepada Tuhan dalam diri pelajar melalui aktiviti pengajaran dan } \\
\text { pembelajaran. }\end{array}$ & 3.82 & Sederhana Tinggi \\
$\begin{array}{l}\text { Sebagai pendidik, saya sedaya upaya menggunakan ilmu mendidik } \\
\text { untuk merangsang perkembangan jiwa pelajar }\end{array}$ & 3.98 & Sederhana Tinggi \\
$\begin{array}{l}\text { Sebagai pendidik, saya berusaha menyuburkan keyakinan pelajar } \\
\text { kepada kehebatan Pencipta yang dibuktikan melalui isi mata } \\
\text { pelajaran yang di ajar. }\end{array}$ & 3.39 & Sederhana \\
$\begin{array}{l}\text { Sebagai seorang pendidik, saya sedaya-upaya membimbing pelajar } \\
\text { agar memiliki pegangan hidup yang betul. }\end{array}$ & 3.45 & Sederhana \\
$\begin{array}{l}\text { Sebagai pendidik, saya menguasai ilmu pengetahuan dengan } \\
\text { mendalam. }\end{array}$ & 3.46 & Sederhana \\
\hline \multicolumn{1}{|c|}{ Purata min } & 3.62 & Sederhana \\
\hline $\begin{array}{l}\text { Item (Tujuan pendidikan; Tanggungjawab sosial: khalifah) } \\
\text { Sebagai pendidik, saya perlu menerapkan pemikiran atau } \\
\text { tanggungjawab seorang khalifah (pemimpin) di dalam diri pelajar, } \\
\text { melalui sebarang aktiviti bersama dengan pelajar di sekolah. } \\
\text { Sebagai pendidik, saya juga bertanggungjawab mendidik akhlak } \\
\text { atau sahsiah pelajar. }\end{array}$ & 4.10 & Tinggi \\
$\begin{array}{l}\text { Saya mendidik pelajar supaya menjadi generasi yang berilmu } \\
\text { pengetahuan. }\end{array}$ & 4.15 & Tinggi \\
$\begin{array}{l}\text { Saya mendidik pelajar supaya menjadi generasi yang berakhlak } \\
\text { mulia. } \\
\text { Saya mendidik pelajar supaya menjadi generasi yang } \\
\text { bertanggungjawab kepada diri, agama, negara dan bangsa. }\end{array}$ & 4.18 & Tinggi \\
\hline \multicolumn{1}{|c|}{ Purata min } & 4.01 & Tinggi \\
\hline PURATA KESELURUHAN & 4.04 & Tinggi \\
\hline
\end{tabular}

Hasil analisis menunjukkan purata min keseluruhan (3.86) berada di tahap sederhana tinggi. Dapatan ini menunjukkan tahap pengetahuan pendidik tentang tujuan pendidikan berada pada tahap sederhana tinggi.

Analisis secara keseluruhan menunjukkan item-item yang berkaitan dengan tujuan pendidikan untuk melahirkan pelajar berilmu, berakhlak mulia dan bertanggungjawab sebagai pemimpin mendapat min pada tahap tinggi. Dapatan ini menunjukkan secara amnya bakal guru faham tentang matlamat sosial proses pendidikan.

Namun apabila di analisis item-item yang mengukur matlamat atau tujuan pendidikan yang perlu diterapkan melalui proses pendidikan sebagai asas untuk melahirkan insan berakhlak mulia iaitu kepercayaan dan keyakinan kepada Pencipta, tahap kefahaman bakal pendidik berada pada tahap sederhana. Dapatan ini menjelaskan kefahaman guru tentang tujuan proses pendidikan untuk memantapkan kepercayaan dan keyakinan pelajar kepada Pencipta melalui ilmu intelektual masih perlu dimantapkan.

\subsection{PERBINCANGAN DAN KESIMPULAN}

Bakal guru berjiwa pendidik seharusnya jelas tentang makna dan matlamat pendidikan. Dapatan kajian menunjukkan pengetahuan bakal guru tentang tujuan utama pendidikan iaitu 
mendidik manusia tentang keyakinan dan kepercayaan kepada Tuhan Pencipta sekalian alam berada pada tahap sederhana. Bagi melahirkan generasi masa hadapan yang mempunyai daya intelektual yang tinggi, sihat dari sudut mental, fizikal dan sahsiah, adalah menjadi tanggungjawab setiap warga pendidik untuk menerapkan nilai kepercayaan dan keyakinan kepada Pencipta (Hasan Langgulung, 1983). Malah proses pendidikan itu tidak dikatakan mendidik selagi ia tidak mengajar manusia mengenal Tuhannya. Maka, pendidikan untuk melahirkan guru berjiwa pendidik seharusnya menekankan elemen ini bagi memastikan bakal guru yang dilahirkan benar-benar jelas tentang visi pendidikan.

Pendidikan yang cuba memisahkan nilai ketuhanan atau cuba menyempitkan nilai agama sebagai urusan peribadi sebenarnya telah gagal melahirkan manusia berkualiti tinggi, berjati diri, berprinsip, berpegang teguh kepada kebenaran sehingga mampu memikul tanggungjawab sebagai pemimpin perubahan dan seterusnya membangunkan proses ketamadunan negara bangsa. Dapatan kajian menunjukkan bakal guru sedar tentang kepentingan pendidikan untuk melahirkan manusia berakhlak, berilmu pengetahuan dan bertanggungjawab. Namun pengetahuan ini akan menjadi sukar untuk di realisasikan di alam kerjaya nanti sekiranya guru tidak jelas tentang matlamat yang memandu proses pembangunan akhlak pelajar. Ibaratnya ingin membuat rumah (hasil yang nampak) tetapi asasnya tiada (bersifat tidak nampak) Corak pendidikan sebeginilah yang akan menjejaskan proses membangunkan jati diri pelajar (Wan Mohd. Nor, 2005).

Orientasi pendidikan tanpa matlamat universal yang jelas mungkin hanya akan berakhir dengan berbagai matlamat material seperti pendidikan untuk kerjaya, pendidikan untuk kepentingan peningkatan taraf ekonomi atau pendidikan untuk kepentingan diri sendiri sahaja. Secara tidak langsung kepentingan pendidikan untuk membangunkan potensi spiritual manusia akan terpingir. Dalam keadaan ini, adalah lebih sukar untuk membangunkan manusia berakhlak dan inilah kesan daripada pendidikan sekular iaitu melahirkan manusia yang berfikir secara terpisah diantara matlamat kehidupan untuk dunia dan akhirat (Ghazali, 1986; Rohana, 2010). Kegagalan mengembangkan proses pendidikan berdasarkan pendekatan integrasi ilmu secara holistik atau integrasi diantara matlamat kehidupan spiritual dan matlamat kehidupan dunia sebagai khalifah menyebabkan manusia gagal memahami dan mengamalkan hidup berlandaskan erti kebebasan yang sebenar. Pemikiran manusia yang tidak merdeka jiwanya akan menjadi jumud, tidak kritikal apatah lagi untuk menjadi seorang yang sensitif dan kreatif (Love dan Talbot, 1999).

Kegagalan meletakkan matlamat yang jelas untuk memimpin pembangunan akhlak pelajar juga menyukarkan guru memainkan peranannya sebagai pendidik. Apa yang berlaku mereka mungkin boleh memainkan peranan sebagai pengajar (mualim) tetapi tidak mungkin dapat memainkan peranan sebagai murabbi (pendidik) yang mampu mendidik dan membimbing perkembangan akal pelajar sehingga terkesan pada jiwa. Tegasnya guru berjiwa pendidik adalah seorang murabbi iaitu pembimbing makna kepada penguasaan ilmu akal bukan sekadar seorang mualim atau pengajar (Muhammad Jihad, 2008).

Oleh itu bagi meningkatkan lagi kualiti bakal pendidik adalah disarankan agar usaha memantapkan pembangunan guru berjiwa pendidik yang memahami matlamat pendidikan dan proses pendidikan integrasi holistik iaitu pembangunan potensi spiritual melalui ilmu intelektual perlulah dilaksanakan.

\section{Rujukan}

Abdul Ghani Azmi. 2002. Himpunan Hadith-Hadith Shahih. Jilid Tiga. Kuala Lumpur: Al-Hidayah Publishers.

Awang Hadi Salleh. 1998. Latihan Perguruan untuk Sekolah Berkesan Prosiding Kebangsaan JPPG, Pendidikan Guru untuk Sekolah Berkesan. Kuala Lumpur: Universiti Malaya.

Azizi Yahya et al. 2006. Menguasai Penyelidikan Dalam Pendidikan. ${ }^{\text {st }}$ ed. Kuala Lumpur: PTS Publications \& Distributors Sdn Bhd.

Berita Harian Online: Capaian pada 28 Julai 2008 http://perkhidmatanpelajaran.blogspot.com/2008/07/guru-perlu-fokusaspek-keperibadian.html.

Hasan Langgulung. 2003. Asas-Asas Pendidikan Islam. Jakarta: Penerbit Pustaka Husna Baru.

Imam Al Ghazali. 1980. Ihya Ulumiddin. Indonesia: Percetakan Menara Kudus

Jahangir Mahmud. 2010. How The Messenger of Allah s.a.w. Taught His Student. Pakistan:Al-misbah.

Ee Ah Meng. 1988. Pendidikan di Malaysia Untuk Guru Pelatih. $2^{\text {nd }}$ ed. Kuala Lumpur, Malaysia: Penerbit Fajar Bakti Sdn Bhd.

Muhammad Jihad. 2008. Bila yang cerdik tetapi tidak baik. Dlm. Telaga Biru. Majalah Solusi. Selangor:Vivar Printing Sdn Bhd. 21-22.

Muhammad Nurfahmi Mohamed et al. 2011. Kemantapan Penghayatan Guru Terhadap Falsafah Pendidikan Kebangsaan Asas Membangunkan Guru Cemerlang. Journal of Edupres. 1(September 2011): 271-278.

Ragbir Kaur a/p Joginder Singh. 2007. Panduan Ulangkaji Pendidikan Untuk KPLI Sekolah Menengah dan Sekolah Rendah. Kumpulan Budiman Sdn. Bhd. Kuala Lumpur.

Ragbir Kour. 2007. Peranan Guru Membina Murid Menghadapi Cabaran Wawasan 2020. Jurnal Penyelidikan Pendidikan Institut Perguruan Islam. 10: 2007-88.

Rashidy Jamil al-Rashi. 2011. Mendidik Nafsu Pendidik. Dlm. Telaga Biru. Majalah Solusi. Selangor:Vivar Printing Sdn Bhd. 35.

Rashidy Jamil al-Rashi. 2011. Akhlak Pendidik. Dlm. Telaga Biru. Majalah Solusi. Selangor:Vivar Printing Sdn Bhd. 35.

Rohana Hamzah. 2009a. Development And Evaluation Of The Holistic Self Developement Modules: A Study Among Arts And Design Students.Universiti Teknologi Mara. Shah Alam: Tesis Doktor Falsafah

Rohana Hamzah. 2009b. Mengenali Manusia Asas Pembangunan Pendidikan Berkualiti. Siri Monograf. Skudai: Penerbit Universiti Teknologi Malaysia.

Sidek Baba. 2011. Tajdid Ilmu Dan Pendidikan. Techknowlogic Trading Sdn.Bhd: Kuala Lumpur. 